\title{
Heart Rate Variability and Muscle Strength in Young Male Adults with Sedentary Behaviour
}

\author{
Norsham Juliana ${ }^{1}$, Zolkafi MAA ${ }^{2}$, Azmani $S^{1}$, Abu $\mathrm{IF}^{3}$, Mon Sarip $\mathrm{NA}^{4}$, Abu Yazit NA ${ }^{1}$, Nur Islami \\ Teng $\mathrm{MF}^{5}$, Das $\mathrm{S}^{6}$ \\ ${ }^{1}$ Faculty Medicine and Health Science, Universiti Sains Islam Malaysia, Nilai, Malaysia \\ ${ }^{2}$ Sultan Idris Education University, Tanjung Malim, Malaysia \\ ${ }^{3}$ Universiti Kuala Lumpur, Kajang, Malaysia \\ ${ }^{4} \mathrm{KPJ}$ Healthcare University College, Malaysia \\ ${ }^{5}$ Faculty of Health Science, Universiti Teknologi MARA, Malaysia \\ ${ }^{6}$ Faculty of Medicine, Universiti Kebangsaan Malaysia, Malaysia
}

\author{
Keywords \\ cardiovascular, musculoskeletal, autonomic \\ function, sedentary behaviour \\ Corresponding Author \\ AP Dr Norsham Juliana \\ Faculty Medicine and Health Science \\ Universiti Sains Islam Malaysia \\ Pandan Indah, 51600 Kuala Lumpur, \\ Malaysia \\ Tel: +06-7978623 \\ Email: njuliana@usim.edu.my \\ Received: 22 October 2020; Accepted: 10 May \\ 2021 \\ Doi: https://doi.org/10.31436/imjm.v20i4
}

\begin{abstract}
INTRODUCTION: Sedentary behaviour or physical inactivity has been relatively prevalent among young adults globally. Multiple studies pointed out that Malaysia has been listed as one of the Asian countries with high prevalence of inactivity. Objective: This study aimed to examine the heart rate variability (HRV) and muscle strength among young adults with sedentary behaviour in order to explore the early impact of this behaviour on their physiological and physical health. MATERIALS AND METHODS: This cross-sectional study involved 185 healthy male adults aged 18-25 years. Participants' height and body compositions were measured and their level of physical activities were obtained using Short Questionnaire to Assess Health (SQuASH). Those with less than 150 minutes per week of physical activity engagement were classified as sedentary. Their HRV was analysed as a determinant for early physiological change that was influenced by the sedentary behaviour. Muscle strength of upper and lower body was assessed via handheld dynamometer to identify the physical fitness associated to the behaviour. RESULTS: Among the participants that volunteered in this study, approximately $44 \%$ were classified as sedentary. Analyses revealed that those with sedentary behaviour had lower variability of their HRV and lower muscle strength as compared to those who engaged with at least 150 minutes per week of physical activities. CONCLUSION: The highlighted evidence of the difference on parameters of HRV and muscle strength with this behaviour suggested that these were the suitable parameters to be utilised in determining subclinical improvement on health with any intervention to curb sedentary behaviour.
\end{abstract}

\section{INTRODUCTION}

Sedentary Behaviour Research Network (SBRN) proposes sedentary behaviour as any waking behaviour with an energy expenditure of $\leq 1.5 \mathrm{METs}$ (metabolic equivalent of task), either in sitting or reclining posture. ${ }^{1}$ Sedentary lifestyle has become a rising burden among South East Asia population including Malaysia. Studies in 2016 revealed that $60 \%$ adults in Malaysia aged 18-77 were physically inactive. ${ }^{2}$ Studies have listed a wide range of contributing factors that could affect one's physical activity including age, race, ethnicity, education level and economic status.,3 The rise of sedentary lifestyle in the past decade has further increased the risk towards noncommunicable diseases (NCD) in the population. The superior prevention strategies for non-communicable diseases has always been the involvement of physical activity in daily life. In order to promote those who are in sedentary behaviour to active lifestyle, wide range of activities have to be provided as choices. ${ }^{4}$ However, there is lacking standardised parameters to be utilised to reflect the effect of various types of activities on health especially on subjects who are healthy at subclinical phase.

Heart rate variability (HRV) is a subclinical marker for heart problems that is widely used to characterise the functions of autonomic nervous system (ANS). ${ }^{5}$ Heart rate fluctuates throughout the day following circadian rhythm, hence the HRV provides information on the integrity of cardiovascular system control. Besides, the parameter has also been described as an independent predictor of mortality in a 
number of prospective epidemiological studies. ${ }^{6}$ Interestingly, the assessment of HRV that is versatile and non-invasive suits to be done at any site without any restriction of clinical settings.

Another body system that is susceptible to be affected due to the sedentary behaviour is the musculoskeletal system. ${ }^{7}$ Any regression of physical activities for 6 months will significantly reduce the integrity of muscle strength. ${ }^{8}$ It is imperative to monitor the muscle integrity of upper and lower extremities in identifying the risk of disability, physical frailty and dependency that may occur at later life. ${ }^{9}$ The aim of the study is to examine the differences of heart rate variability (HRV) and muscle strength in young adults with sedentary behaviour in order to identify the early impact of this behaviour on their physiological and physical health.

\section{MATERIALS AND METHODS}

\section{Study sample}

This cross-sectional study was carried out in 2018 among 150 healthy young male adults (18-35 years old). The sample size was attained using Cochran's formula. ${ }^{10}$ Subjects were recruited from few institutions and community centres at Klang Valley and Negeri Sembilan, Malaysia. Since gender differences may result in different HRV reading, only male subjects are recruited in this study. Written consent was obtained from the subjects prior conducting the study. Respondents with metabolic syndrome, non-communicable or communicable diseases, musculoskeletal disorders, history of fall, history of motor vehicle accident (which can cause reduced muscle strength due to accidents) and known postural hypotension problem (to avoid subject from fainted during performing HRV test) were excluded from the study. The study protocol was reviewed and approved by the Universiti Sains Islam Malaysia Ethics Committee (USIM/ REC/0416-3). All tests were done in a close air-conditioned room with estimated room temperature of $24.0-26.5^{\circ} \mathrm{C}$.

Respondents' heights were measured using InBody BSM170/170B Stadiometer (Inbody, Seoul, Korea), whilst their weight and body composition was determined via InBody 270 Body Impedance Analyser (Inbody, Seoul, Korea). Classifications of physical activity were based on Short Questionnaire to Assess Health-Enhancing Physical Activity (SQuASH) as recommended by Juliana et al. ${ }^{11}$ Respondents were requested to fill in the average duration (hours and minutes), intensity (low, moderate, high) and frequency of specific types of physical activity they were engaged in per week. Respondents who performed less than 150 minutes of moderate or 75 minutes of vigorous intensity of physical activity per week were categorised as sedentary. ${ }^{12}$ IMJM Volume 20 No.4, October 2021

\section{Heart rate variability measurement}

Short-term HRV analysis was assessed using the Actiheart HRV monitoring device (CamNtech; UK). The Actiheart electrodes were attached to respondents' chests at the level of V4 and V5 (5 ${ }^{\text {th }}$ intercostal space) prior starting the test. The time and frequency domains were recorded. Respondents were instructed to perform Valsalva Manoeuvre (VM) in sitting position and Orthostatic Tolerance Test (OTT) in supine and standing position to stimulate both sympathetic and parasympathetic nervous systems. Prior starting each test, respondents were requested to rest for 10 minutes. The HRV was recorded starting from respondent's resting state until they completed all tests. They performed VM by exhaling into a mouthpiece fixed to a mercury manometer with standard sphygmomanometer tubing while subjects maintained a 40 mmHg column for 15 seconds. Blood pressure was measured in supine and standing positions after 15 minutes of rest using OMRON HEM-7120 Automatic Blood Pressure Monitor (Japan). OT'T data was processed for 15 seconds during standing after being in supine position. Each respondent repeated the OTT three times and the mean was calculated. The results of postural mean blood pressure index (PMBPI) [(quick standing mean blood pressure - recumbent mean blood pressure)/ quick standing mean blood pressure X 100] were categorised into three: more than $0.05 \%$ as good, $0.05 \%$ to $-18.0 \%$ as moderate and less than $-18.0 \%$ as poor. ${ }^{13}$ The HRV analyses were done using Actiheart 4 software that includes time and frequency domains.

\section{Muscle strength measurement}

JTech Commander Power Track MMT (JTech Medical; USA) was used to assess muscle strength and the force was recorded in Newton $(\mathrm{N})$, measured to the nearest $0.1 \mathrm{~N}$. The handheld dynamometer was used to measure force generated by groups of muscles involved. Respondents were requested to perform maximum isometric contraction during the dynamometry measurement. The dynamometer was placed perpendicular to subjects' tested limbs and all tests were done in supine position except for knee flexion and extension which were done in sitting position. The muscles that were tested include elbow flexors, elbow extensors, shoulder abductors, knee flexors, knee extensors, and hip abductors. The muscle strength tests were performed by a well-trained healthy examiner as the examiner must apply resistance to avoid movements of the tested limbs. One-minute gaps were given between two consecutive trials for each group of muscles. The highest force produced during each session was recorded as respondent's muscle strength. Test sequence started with assessment of the upper body followed by the lower body. 


\section{Data analysis}

Normality tests were done. The normality test revealed that muscle strength variables were normally distributed and a parametric test could be used. However, distributions of some HRV variables significantly differed from the normal distribution and a non-parametric test was preferred. Hence, the differences between active and sedentary groups were examined using Mann Whitney U-Test for HRV variables and independent $\mathrm{t}$-test for muscle strength. The significance was set at $p<0.05$. The data was analysed using the IBM Statistical Package for the Social Sciences version 24.0 software (USA).

\section{RESULTS}

There were 185 respondents volunteered in this study with the mean age of 21.3 . Approximately $44.34 \%$ of the respondents were classified as sedentary. This study revealed that there was a significantly higher body mass index (BMI) and fat percentage among the sedentary group (Table I).

Table I Body composition profiles according to lifestyle preferences

\begin{tabular}{llll}
\hline Profiles & $\begin{array}{l}\text { Active }(\mathrm{n}=103) \\
\text { Mean } \pm \text { SD }\end{array}$ & $\begin{array}{l}\text { Sedentary } \\
(\mathrm{n}=82) \\
\text { Mean } \pm \mathrm{SD}\end{array}$ & p value \\
\hline Anthropometry Profiles & $21.15 \pm 2.48$ & $21.53 \pm 1.51$ & 0.19 \\
Age (years) & $168.3 \pm 7.0$ & $167.0 \pm 7.2$ & 0.15 \\
$\begin{array}{l}\text { Height }(\mathrm{cm}) \\
\text { Weight }(\mathrm{kg})\end{array}$ & $68.0 \pm 14.2$ & $72.4 \pm 19.9$ & 0.13 \\
$\begin{array}{l}\text { BMI (kgm-2) } \\
\text { Body Impedance }\end{array}$ & $24.1 \pm 4.9$ & $25.9 \pm 6.2$ & $0.04^{*}$ \\
$\begin{array}{l}\text { Profiles } \\
\text { Percent body fat (\%) }\end{array}$ & $20.5 \pm 4.1$ & $25.9 \pm 10.0$ & $0.001^{* *}$ \\
$\begin{array}{l}\text { Skeletal muscle mass } \\
\text { (kg) }\end{array}$ & $29.0 \pm 5.0$ & $28.5 \pm 5.8$ & 0.51 \\
\begin{tabular}{l} 
Total body water (L) \\
\hline
\end{tabular} & $37.8 \pm 5.7$ & $37.3 \pm 7.1$ & 0.60 \\
\hline
\end{tabular}

HRV and muscle strength between active and sedentary groups

Results found that those who were sedentary had lower variability compared to those who were active (Table 2). Sedentary males showed a significantly lower mean rank in $\mathrm{LF} / \mathrm{HF}$ during Valsalva manoeuvre $(p=0.003)$. Results from the OTT revealed that the average maximum $\mathrm{R}-\mathrm{R}$ values, average minimum $\mathrm{R}-\mathrm{R}$ values, low frequency and high frequency were also lower in the sedentary group ( $p \leq 0.034)$. Besides having a lower variability, sedentary males were also found to have significantly lower muscle strength for all groups of muscles than those who were active $(p \leq .029)$.
Table II HRV and muscle strength according to lifestyle preferences

\begin{tabular}{|c|c|c|c|}
\hline Profiles & $\begin{array}{l}\text { Active } \\
(\mathrm{N}=103) \\
(\text { median } \pm \mathrm{IQR} \\
/ \text { mean } \pm \mathrm{SD}) \\
\end{array}$ & $\begin{array}{l}\text { Sedentary } \\
(\mathrm{N}=82) \\
(\text { median } \pm \mathrm{IQR} \\
/ \text { mean } \pm \mathrm{SD})\end{array}$ & p-value \\
\hline \multicolumn{4}{|l|}{$\begin{array}{l}\text { HRV } \\
\text { Valsalva Manoeuvre }\end{array}$} \\
\hline $\begin{array}{l}\text { Maximum R-R } \\
\text { values (ms) }\end{array}$ & $933 \pm 147$ & $937 \pm 171$ & 0.844 \\
\hline $\begin{array}{l}\text { Minimum R-R } \\
\text { values (ms) }\end{array}$ & $675 \pm 9$ & $662 \pm 91$ & 0.458 \\
\hline $\begin{array}{l}\text { Max/Min R-R } \\
\text { values (ms) }\end{array}$ & $1.4 \pm 0.3$ & $1.4 \pm 0.3$ & 0.486 \\
\hline $\begin{array}{l}\text { standard deviation } \\
\text { R-R values (SDNN) } \\
(\mathrm{ms})\end{array}$ & $75.7 \pm 30.8$ & $83.1 \pm 40.2$ & 0.340 \\
\hline $\begin{array}{l}\text { Low Frequency } \\
(\mathrm{LF})\left(\mathrm{ms}^{2}\right)\end{array}$ & $2054 \pm 1874$ & $2358 \pm 1945$ & 0.307 \\
\hline $\begin{array}{l}\text { High Frequency } \\
(\mathrm{HF})\left(\mathrm{ms}^{2}\right)\end{array}$ & $512 \pm 702$ & $1157 \pm 1832$ & $0.004^{*}$ \\
\hline Ratio LF/HF & $8.0 \pm 8.4$ & $4.8 \pm 4.3$ & $0.010^{*}$ \\
\hline \multicolumn{4}{|l|}{ Orthostatic Tolerance Test } \\
\hline $\begin{array}{l}\text { Maximum R-R } \\
\text { values (ms) }\end{array}$ & $1145 \pm 244$ & $1072 \pm 241$ & $0.034^{*}$ \\
\hline $\begin{array}{l}\text { Minimum R-R } \\
\text { values (ms) }\end{array}$ & $561 \pm 75$ & $556 \pm 67$ & 0.551 \\
\hline $\begin{array}{l}\text { Max/Min R-R } \\
\text { values (ms) }\end{array}$ & $2.1 \pm 0.6$ & $1.9 \pm 0.5$ & 0.066 \\
\hline SDNN (ms) & $122.5 \pm 63.9$ & $97.1 \pm 42.0$ & $0.001 * *$ \\
\hline $\begin{array}{l}\text { Low Frequency } \\
\left(\mathrm{ms}^{2}\right)\end{array}$ & $3022 \pm 9652$ & $2096 \pm 4546$ & 0.177 \\
\hline $\begin{array}{l}\text { High Frequency } \\
\left(\mathrm{ms}^{2}\right)\end{array}$ & $1729 \pm 5893$ & $1037 \pm 2715$ & 0.174 \\
\hline Ratio LF/HF & $2.9 \pm 1.7$ & $3.1 \pm 2.0$ & 0.729 \\
\hline \multicolumn{4}{|l|}{ Blood Pressure } \\
\hline $\begin{array}{l}\text { Postural mean } \\
\text { blood pressure } \\
\text { index (PMBPI) } \\
(\mathrm{mmHg})\end{array}$ & $8.0 \pm 5.6$ & $7.8 \pm 6.9$ & 0.909 \\
\hline \multicolumn{4}{|l|}{$\begin{array}{l}\text { Muscle strength } \\
\text { Upper body strength }(\mathrm{N})\end{array}$} \\
\hline Elbow flexors & $158.4 \pm 34.7$ & $133.4 \pm 40.1$ & $0.001^{* *}$ \\
\hline Elbow extensors & $139.7 \pm 33.8$ & $122.8 \pm 30.2$ & $0.001 * *$ \\
\hline $\begin{array}{l}\text { Shoulder } \\
\text { abductors }\end{array}$ & $148.1 \pm 31.1$ & $122.8 \pm 29.8$ & $0.001 * *$ \\
\hline \multicolumn{4}{|l|}{$\begin{array}{l}\text { Lower body strength } \\
(\mathrm{N})\end{array}$} \\
\hline Knee flexors & $131.7 \pm 37.4$ & $114.3 \pm 38.3$ & $0.007^{*}$ \\
\hline Knee extensor & $157.0 \pm 42.7$ & $141.0 \pm 46.3$ & $0.029 *$ \\
\hline Hip abductors & $149.5 \pm 32.9$ & $133.9 \pm 40.5$ & $0.011 *$ \\
\hline
\end{tabular}

* significance value at $p<.05$ based on Mann-Whitney-U-test for HRV, and independent $t$-test for muscle strength

** significance value at $p<.001$ based on Mann-Whitney-U-test for HRV, and independent $t$-test for muscle strength 


\section{DISCUSSION}

Sedentary behaviour is commonly defined as any waking behaviour characterised by an energy expenditure of $\leq 1.5$ METS while being in a sitting or reclining posture. ${ }^{1}$ This definition by the Sedentary Behaviour Research Network is based on the intensity of physical activity engaged together with the posture involved. ${ }^{5,16}$ Tudor-Locke (2012) suggested that $<5000$ steps per day is an indicative measure that also can be used to define sedentary behaviour. ${ }^{17}$ All these measures are validated and can be utilised interchangeably to define sedentary behaviour. Based on SQuASH questionnaire, discrimination between those who are active and sedentary can be easily done using the calculation of minute/week and activity score in the leisure time activity domain. ${ }^{18}$

South East Asia countries including Malaysia have been affected by the rising trend of physical inactivity and sedentary behaviour. The prevalence of $48.1 \%$ sedentary behaviour among males in this study is in accord with a recent study by Peltzer and Pengpid (2019). ${ }^{19}$ They found out that $42.7 \%$ of Malaysian adolescents among their large sample study were sedentary. The slight differences between the studies is probably due to the age group of young adults that involves in the study. Besides Malaysia, the rate of sedentary behaviour in neighbouring countries such as Cambodia, Philippines, Indonesia, Myanmar and Thailand are also worrying ranging from $10.5 \%$ to more than $30 \%$ in some areas. ${ }^{19}$ Studies from recent decades have pointed out that sedentary behaviour has been inflicting all age ranges from children up to the elderly, hence the unhealthy lifestyle indicates an alarming risk of global health burden., 20-21

Estimation of sedentary behaviour in this study was based on males' physical activity that was assessed via SQuASH questionnaire. The questionnaire was validated and previously utilised in multiple studies in Malaysia. ${ }^{18}$ Uniquely, SQuASH was designed to suit repeated physical activity measurement for estimation of compliance to certain physical activity guidelines and the questionnaire was reported as reliable to be used for patients or healthy subjects. $^{22}$ Study has also proven that the SQuASH questionnaire is a valid self-reporting tool to measure physical activity energy expenditure in young adults. ${ }^{23}$ Most physical activity questionnaires like the Baecke Habitual Physical Activity Questionnaire (BHPAQ) and the Vorrips questionnaire are not designed to estimate compliance of any guidelines. ${ }^{24}$ The SQuASH questionnaire was designed to assess four categories of activities; commuting, recreational activity, nature of work and household activity. Categorisation of different domains allows for specific measurement of leisure time activities based on WHO characteristics. ${ }^{25}$

HRV analysis is widely used to characterise the functions of the autonomic nervous system (ANS) and the subclinical marker for heart problems. Generally, there are several factors that influence individual HRV such as hormonal and neural modulations, circadian changes, exercise, emotions, posture and preload. ${ }^{26}$ This study focused on short-term HRV by stimulating the autonomic nervous system via VM and OTT. Short-term HRV is a convenient method to assess subjects in out-of-hospital settings. However, there are still limited studies available involving short-term HRV analysis that provides statistically relevant reference values for linear and nonlinear HRV indices from healthy subjects. ${ }^{27}$ Therefore, this study is imperative to add reference values on the variation of short-term HRV with either sedentary or active lifestyle.

Recent studies have proven that short-term HRV analysis has been utilised in studies related to fall prediction, detection of mental stress and detection of training efficacy. ${ }^{28-30}$ Based on this study, sedentary males showed significantly poor HRV as compared to subjects with active lifestyle. The findings prove that variation of HRV can be seen in early adulthood. In addition to the significant finding, the autonomic variations in SDNN among subjects with active lifestyle were also higher. Earlier studies revealed that the ratio of LF and HF spectral analysis was sensitive to the changes in ambient temperature. Therefore, the data collection was done under a controlled ambient temperature of $25^{\circ}-27^{\circ} \mathrm{C}$ to avoid any thermal bias between the two groups. ${ }^{31}$ It was observed that within the controlled environment, a significantly higher LF/HF reading was recorded in the active group during VM. Hence, the result indicated that there was a higher sympathetic nerve stimulation found among them. Previous studies by Lizamore et al. have shown that 4 weeks of alteration in physical activity among adolescents significantly increased the HRV among their subjects and another intervention utilising adult population by Jones et al. have shown that 12 weeks of intervention has desirable intervention effects on HRV. 32,33

The present study shows that there were significant differences in muscle strength between the sedentary and active groups. BMI is a part of the determinant for muscle strength, however, higher BMI in sedentary males for this study did not show any positive impact on muscle strength in the upper and lower body. High BMI that cause by high muscle mass would lead to better muscle strength. However, the higher BMI in sedentary subjects is contributed from the significantly higher body fat percentage. According to WHO, body fat of more than 24.9 is above normal value for adults. ${ }^{34}$ Results from this study align with findings of previous studies 
that pointed out the upper body muscle strength of more than $155.7 \mathrm{~N}$ is found in those who are active.7,35 Preserving muscle integrity is important in preventing disability, physical frailty, fall and dependency in later life. ${ }^{36}$ This situation warrants serious attention as a recent study in 2016 have revealed that $60 \%$ of Malaysian adults are classified as sedentary. ${ }^{2}$

The main limitation in this study involves the SQuASH questionnaire in which it is unable to specifically discriminate the specific duration of inactivity that significantly results in different HRV findings between the two groups. Another limitation that has been extensively debated in current research studies is the spectral analyses in pointing out the value that can be utilised as reference for either sympathetic or parasympathetic nerves stimulation. The gaps between studies may be due to the influence of artefacts between the studies. The conclusions of each work are still valid as the spectral analyses are interpreted based on the context of each study. ${ }^{37}$

\section{CONCLUSION}

This study indicates that the cardiovascular and musculoskeletal systems are highly impacted with sedentary behaviour at early age. Engagement in daily physical activities showed desirable balance in the function of autonomic nervous systems, hence reduces the risk towards cardiovascular diseases in later life. Furthermore, being active also preserves muscle strength that is important in maintaining quality aging. Future studies must emphasise on specific physical activities that are able to reverse autonomic imbalance and low muscle strengths due to sedentary lifestyle. Finally, parameters of HRV and muscle strength was found to be suitable markers to determine the changes brought by physical activities on physical health.

\section{CONFLICT OF INTEREST}

We declared no conflict of interest.

\section{ACKNOWLEDGEMENTS}

We wish to acknowledge the participants in this study and the collaborating universities. This work was supported by the Universiti Sains Islam Malaysia Grant, grant number: USIM/UKM/RCRP/FPSK/052002/71017.

\section{REFERENCES}

1. Tremblay MS, Aubert S, Barnes JD, et al. Sedentary Behavior Research Network (SBRN) - Terminology Consensus Project process and outcome. Int J Behav Nutr Phys Act 2017; 14.

2. Cai LT, Bonn G, Si Han Y, Chin Choo Y, Chee Piau W. Physical activity and its correlates among adults in malaysia: a cross-sectional descriptive study. PLOS ONE. 2016; 11.

3. Al-Hazzaa HM, Abahussain NA, Al-Sobayel HI, Qahwaji DM, Musaiger AO. Physical activity, sedentary behaviors and dietary habits among Saudi adolescents relative to age, gender and region. International Journal of Behavioral Nutrition and Physical Activity. 2011; $8: 140$.

4. Thayer JF, Yamamoto SS, Brosschot JF. The relationship of autonomic imbalance, heart rate variability and cardiovascular disease risk factors. International Journal of Cardiology. 2010; 141: 122-131.

5. Jaiswal M, Urbina EM, Wadwa RP, et al. Reduced heart rate variability among youth with type 1 diabetes. Diabetes Care. 2013; 36: 157-162.

6. Pieters N, Plusquin M, Cox B, Kicinski M, Vangronsveld J, Nawrot TS. An epidemiological appraisal of the association between heart rate variability and particulate air pollution: a meta-analysis. Heart. 2012; 98: 1127

7. Cools AMJ, Vanderstukken F, Vereecken F, et al. Eccentric and isometric shoulder rotator cuff strength testing using a hand-held dynamometer: reference values for overhead athletes. Knee Surgery, Sports Traumatology, Arthroscopy. 2016; 24: 3838-3847.

8. Moriyama Y, Hara M, Aratani S, Ishikawa H., Kono K, Tamaki M. The association between six month intradialytic resistance training and muscle strength or physical performance in patients with maintenance hemodialysis: a multicenter retrospective observational study. BMC Nephrology. 2019; 20: 172.

9. Juliana N, Abu IF, Roslan NA, Mohd Fahmi Teng NI, Hayati AR, Azmani S. Muscle Strength in Male Youth that Play Archery During Leisure Time Activity. In: Enhancing Health and Sports Performance by Design, Singapore, Springer Singapore. 2020.

10. Gregoire TG, Affleck DLR. Estimating Desired Sample Size for Simple Random Sampling of a Skewed Population. The American Statistician. 2018; 72: 184190.

11. Juliana N, Shahar S, Sahar MA, Ghazali AR, Manaf ZA, Noah RM. 'Her shape' intervention programme for obese women with high breast adiposity. Asia Pac J Clin Nutr. 2017; 26(2): 278-286. 
12. World Health Organization. Global Recommendations on Physical Activity for Health. Switzerland: WHO Publication. 2010.

13. Juliana N, Nadia ME, Roslan NA, et al. Comparison of heart rate variability among malay male young adult with different bmi and level of adiposity. The International Medical Journal Malaysia. 2019; 18(1): $73-$ 79 .

14. Ghasemi A, Zahediasl S. Normality tests for statistical analysis: a guide for non-statisticians. International journal of endocrinology and metabolism. 2012; 10(2): 486-489.

15. Gibbs BB, Hergenroeder AL, Katzmarzyk PT, Lee IM, Jakicic JM. Definition, measurement, and health risks associated with sedentary behavior. Medicine and science in sports and exercise. 2015; 47(6): 1295-1300.

16. Rivière F, Aubert S, Omorou AY, Ainsworth BE, Vuillemin A. Taxonomy-based content analysis of sedentary behavior questionnaires: A systematic review. PLOS ONE. 2018; 13(3).

17. Tudor-Locke C, Craig CL, Thyfault JP, Spence JC. A step-defined sedentary lifestyle index: $<5000$ steps/day. Applied Physiology, Nutrition, and Metabolism. 2012; 38(2): 100-114.

18. Juliana N, Akmal NI, Johari SM, Azmani S, Umaisara NA, Amin NA. Recommended Physical Activity and Intensity Levels to Reduce Excess of Body Fat Amongst Malay Female University Students in Malaysia. Journal of. Fundamental and Applied Science. 2017; 9: 111-121.

19. Peltzer K, Pengpid S. Leisure Time Physical Inactivity and Sedentary Behaviour and Lifestyle Correlates among Students Aged 13-15 in the Association of Southeast Asian Nations (ASEAN) Member States, 2007-2013. International Journal of Environmental Research and Public Health. 2016; 13(2).

20. Bellettiere J, Carlson JA, Rosenberg D, et al. Gender and age differences in hourly and daily patterns of sedentary time in older adults living in retirement communities. PLOS ONE. 2015; 10(8).

21. Finkel D, Andel R, Pedersen NL. Gender differences in longitudinal trajectories of change in physical, social, and cognitive/sedentary leisure activities. The Journals of Gerontology: Series B. 2016; 73(8): 1491-1500.

22. de Hollander EL, Zwart L, de Vries SI, Wendel-Vos W. The SQUASH was a more valid tool than the OBiN for categorizing adults according to the Dutch physical activity and the combined guideline. Journal of Clinical Epidemiology. 2012; 65(1): 73-81.

23. Nerissa C, Anca G, Casey G, Elaine R, Ralph M, Harry P. The Short Questionnaire to Assess HealthEnhancing (SQUASH) Physical Activity in
Adolescents: A Validation Using Doubly Labeled Water. Journal of Physical Activity and Health. 2016; 13(2): 154 -158 .

24. Sadeghisani M, Dehghan Manshadi F, Azimi H, Montazeri A. Validity and reliability of the persian version of baecke habitual physical activity questionnaire in healthy subjects. Asian Journal Of Sports Medicine. 2016; 7(3).

25. Sørensen L, Mikkelsen LR, Jacobsen JS, Tjur M, Mechlenburg I. Reliability of the Danish version of the short questionnaire to assess health-enhancing physical activity (SQUASH). Physiotherapy Theory and Practice. 2018; 34(8): 637-642.

26. Kuroda Y, Hudson J, Thatcher R. Motivational state and personality in relation to emotion, stress, and hrv responses to aerobic exercise. Journal of Psychophysiology. 2015; 29(4): 147-160.

27. Voss A, Schroeder R, Heitmann A, Peters A, Perz S, Short-term heart rate variability-influence of gender and age in healthy subjects. PLOS ONE. 2015; 10(3).

28. Nakamura FY, Flatt AA, Pereira LA, Ramirez-Campillo R, Loturco I, Esco MR. Ultra-short-term heart rate variability is sensitive to training effects in team sports players. Journal Of Sports Science \& Medicine. 2015; 14 (3): 602-605.

29. Castaldo R, Xu W, Melillo P, Pecchia L, Santamaria L, James C. Detection of mental stress due to oral academic examination via ultra-short-term HRV analysis. 2016 38th Annual International Conference of the IEEE Engineering in Medicine and Biology Society (EMBC). 2016.

30. Castaldo R, Melillo P, Izzo R, Luca ND, Pecchia L. Fall prediction in hypertensive patients via short-term HRV analysis. IEEE Journal of Biomedical and Health Informatics. 2017; 21(2): 399-406.

31. Zhu H, Wang H, Liu Z, Li D, Kou G, Li C. Experimental study on the human thermal comfort based on the heart rate variability (HRV) analysis under different environments. Science of The Total Environment. 2018; 1124-1133.

32. Lizamore C, Kathiravel Y, Elliott J, Hellemans J, Hamlin M. The effect of short-term intermittent hypoxic exposure on heart rate variability in a sedentary population. Acta Physiologica Hungarica. 2016; 103 (1):75-85.

33. Jones SMW, Guthrie KA, Reed SD, et al. A yoga \& exercise randomized controlled trial for vasomotor symptoms: Effects on heart rate variability. Complementary Therapies in Medicine. 2016; 26:66-71.

34. World Health Organization Obesity: Preventing and Managing the Global Epidemic. Report of a WHO Consultation on Obesity. 1998. Geneva: WHO Publication 
35. Daloia LMT, Leonardi-Figueiredo MM, Martinez EZ, Mattiello-Sverzut AC. Isometric muscle strength in children and adolescents using Handheld dynamometry: reliability and normative data for the Brazilian population. Brazilian Journal of Physical Therapy. 2018; 22(6): 474-483.

36. Yang N-P, Hsu N-W, Lin C-H, et al. Relationship between muscle strength and fall episodes among the elderly: the Yilan study, Taiwan. BMC Geriatrics. 2018; 18(1): 90.

37. Rodríguez-Liñares L, Simpson DM. Spectral estimation of HRV in signals with gaps. Biomedical Signal Processing and Control. 2019; 52:187-197. 